\title{
КОРРЕКЦИЯ ОШИБОК РЕЧИ ДЕТЕЙ-БИЛИНГВОВ
}

\author{
Савчук Татьяна Николаевна \\ Ивкина Олеся Георгиевна \\ Буденная Елена Геннадьевна \\ Афанасьева Валентина Андреева \\ МАОУ СОШ №14 г. Балашиха
}

Аннотация. $\mathrm{B}$ данной статье рассматриваются наиболее распространенные речевые и языковые трудности детей-билингвов. Изучался процесс формирования речевой деятельности у детей-билингвов, а в качестве предмета исследования выступает речевая стратегия родителей. $\mathrm{B}$ соответствии с рекомендациями $\mathrm{BO} 3$ и рекомендациями зарубежных методистов нами были сформированы семь ключевых приемов для плавной интеграции ребенка в мульти национальное общество.

Ключевые слова: дети-билингвы, билингвизм, недоминантный язык, монолингвальные нормы, инпут.

\section{ERRORS CORRECTION OF BILINGUAL CHILDREN'S SPEECH}

\section{Savchuk Tatyana Nikolayevna Ivkina Olesya Georgievna Budennaya Elena Gennadievna Afanasyeva Valentina Andreyevna}

\begin{abstract}
This article reveals the most common speech and language difficulties of bilingual children. We studied the formation process of bilingual children's speech activity and the speech strategy of parents serves as the subject of our research. In accordance with recommendations of World Health Organization and foreign methodologists we have formed seven key techniques for the constant integration of a child into a multi-national society.
\end{abstract}

Keywords: children-bilinguals, bilingualism, non-dominant language, monolingual norms, input.

Вопросы воспитания никогда не теряли актуальности. А в условиях глобализации - и, как следствие, образования межкультурных и межязыковых единиц общества - они становятся настолько востребованы, что поворот к 
педагогике, как комплексному явлению, испытывает всплеск неподдельного интереса как со стороны педагогов, социологов, теоретиков-методистов, так и лингвистов, когнитивистов и специалистов многих смежных специальностей. Связано это прежде всего с неразрывностью процесса формирования речевой деятельности ребенка с процессом социализации в одноязычном, двуязычном или многоязычном обществе. Таким образом, билингвальное, или двуязычное, воспитание детей остро стоит на повестке дня, активно развивается и дискутируется в мировом научном сообществе на междисциплинарном уровне.

В настоящее время термин билингвизм проникает практически во все сферы деятельности человека глобального, становясь, по меткому определению Кубряковой Е.С., зонтиковым: в музыке билингвизм означает способность исполнителя одновременно сочинять и продуцировать музыку, в психологии и психиатрии - раздвоение личности, однако в языкознании и педагогике билингвизм определяется как двойная система самовыражения, двусторонность процесса экспрессии, двойственность кода коммуникации.

Как показал проведённый анализ справочно-методической литературы по поднимаемому вопросу, термин «двуязычие», или «билингвизм», в отечественной педагогике рассматривается как владение языками в такой степени, когда оба используются говорящим достаточно регулярно, причем в естественном общении. Выделение билингвизма - одно из первых социолингвистических открытий. Однако случаи истинного билингвизма не часты, т.к. быть билингвом - значит постоянно пользоваться обоими языками в повседневной жизни и при этом легко, без затруднений переходить с одного языка на другой, не замечая этого перехода.

Отношение к самому феномену билингвизм менялось с течением времени. Например, в дореволюционной России большая часть аристократии в силу своего образования и возможностей перемещения с глубокого детства усваивали по два, три и более иностранных языка, что считалось нормой. В Советском Союзе государственная политика была направлена на популяризацию и становление двуязычия, однако часто детей, использующих два языка в своей речи, называли «страдающими двуязычием». Были распространены случаи, когда логопедам приходилось ставить диагноз двуязычие детям из семей мигрантов, так как любое неполноценное знание русского языка, расценивалось как болезнь и девиация.

Однако уже в наши дни происходит активная пропаганда двуязычного образования и раннего обучения иностранным языкам, как это было в 19 веке, что приводит к осознанию билингвизма в контексте освоения культурных 
ценностей, как важнейшей задачи современного этапа развития цивилизации. Сегодня владение двумя и более языками рассматривается исключительно как положительное явление, и данный факт ни у кого не вызывает сомнения.

Объектом предпринятого исследования является процесс формирования речевой деятельности детей в условиях одновременного усвоения русского и английского языков, а также речевая стратегия родителей (как педагогов) по отношению к ребенку, так как именно она является определяющей составляющей в онтогенезе речи ребенка.

Одна из особенностей общения родителей на двух языках заключается в выборе адекватной стратегии исправления ошибок в речи детей-билингвов. Особенно тщательно ее продумывают родители, носители недоминантного языка. Для большей иллюстративности и убедительности приводим полученные в ходе практического изучения данной проблемы в виде таблицы.

Основная стратегия заключается в том, что исправление ошибок не должно мешать общению с ребёнком. Сам факт их допущения не должен разочаровывать ни родителей, ни самих детей. В этом случае роль взрослого заключается в том, чтобы научить языку. Общение, ориентированное на ребенка, а не на контроль за его речью, приводит к более активному владению языком.

Таблица 1

\section{Примеры высказываний детей билингвов и методические рекомендации по исправлению систематических ошибок}

\begin{tabular}{|l|l|l|}
\hline 1. & $\begin{array}{l}\text { Я вам сейчас придумаю сказку. Во, придумал. Это } \\
\text { офицерская сказка. Жил-был один офицер. А рядом } \\
\text { жили три пионера. Они были такие страшные - с } \\
\text { ножами и большими пистолетами. }\end{array}$ & $\begin{array}{l}\text { Функциональный подход к изуче- } \\
\text { нию высказываний позволяет утвер- } \\
\text { ждать что, несмотря на отсутствие } \\
\text { структурированности и морфологи- } \\
\text { ческого оформления, даже самые } \\
\text { ранние высказывания ребенка пред- } \\
\text { ставляют собой законченное целое, } \\
\text { содержащее определенный смысл, } \\
\text { т.е. в голофразах, однословных дет- } \\
\text { ских высказываниях, тоже имеет } \\
\text { место предикация. }\end{array}$ \\
\hline 2. & $\begin{array}{l}\text { Once upon a time, there lived a chair and a spade. The } \\
\text { chair was standing near the window and reading a } \\
\text { book. The spade was digging the ground. Then the } \\
\text { spade jumped upon the chair, the chair jumped into the } \\
\text { book-case, the book-case jumped into the castle, the } \\
\text { castle jumped into the darkness. The darkness ate the } \\
\text { castle, the castle ate the bookcase, the bookcase ate the } \\
\text { chair, the chair ate the spade. And this is the end of the } \\
\text { fairy-tale. }\end{array}$ \\
\hline
\end{tabular}


3. Papa, I want to tell you a horrid fairy-tale. Once upon a time there lived papa. And there lived Peter. He was very strong, much stronger than the Dragon...

4. Я сочинил стихи, Как я в печали увидел кошку. Я печальный и во сне. Печальный я сплю, И во сне кошка Стукнула хвостом по коробке. И кошка видела во сне.

5. Once upon a time There lived a soldier Who went to the war, Who went to the war. And then he came home, And then he came home For the day, For the day.
Порядок следования элементов может быть как нормативным, так и с отклонениями от нормы. Порядок появления в высказываниях еще не говорит о том, что соответствующие актанты нормативно оформлены в речи. Грамматически правильное оформление синтаксем зависит от того, насколько усвоены морфологические категории и формы.

Все люди делают ошибки в речи, но из-за этого нельзя отказываться от общения. Ошибки постепенно исчезнут, если продолжать разговаривать.

При освоении биграмотности графика и орфография языка, письмо на котором усвоено раньше, могут оказать влияние на письменную речь на следующем языке. Одни ошибки объясняются отождествлением правил орфографии, другие сходством графики в двух языках.

Билингвы склонны обращать внимание на формальную сторону языковых явлений и поэтому усваивают некоторые грамматические конструкции быстрее и с меньшим количеством ошибок, чем многие монолингвы.

Специалисты отмечают способность детей-билингвов более доходчиво объяснять правила своим собеседникам, давать более четкие определения понятий, поскольку они имеют более развитые метакоммуникативные способности, чем их сверстникимонолингвы. мышонок стал маленьким, как крошка хлеба. Потом Клаке пошел к медведю. Он не знал, как опасно подходить к медведю. А потом за ним побежала лиса, но она ничего не увидела. На этом мы остановимся. 
8. Once upon a time there lived a man by the name John and his mother. They had a girl-son and a boy-son, Jill and Jack. He had two houses. One house was made of wood. He built it in the forest on the bank of a lake. The other house was in town. It was made of bricks, stones and blocks. John crashed a lot of people under his sledges but not with the shafts. And tzar La Monti had a daughter by the name Escada and the son by the name Suprimax. John was a criminal and he had another criminal. The tzar had two knights. And John had to go to the tzar La Monti and to beat him because he let his knights kill John's son. The tzar had other knights. Jack struck one knight and he fell dead. Jack struck another knight with a knife but he missed. John struck again and offhis head he cut and he got.

9. (The pilot is a flyer). The pilot had a dog by the name Chappie. He was a big dog. He was a very good dog because he loved the pilot. But the pilot was John's brother. The pilot was named Henry Morgan. The pilot had a mother and a wife and a grandfather and a son by the name Bill. The pilot had four dogs: Chappie, Dobbie, Zoobbie, and Lucky. John was very happy because his brother had many dogs and they were good. The pilot ran to the shop to buy some meat for his dogs and some chickens with bones to gnaw.

10. Сидели две мышки ночью и смотрели на луну, на месяц. Они увидели, что месяц стал совсем маленьким. Мышки спросили летучих мышей: «Кто это там ест месяц? Нельзя ли и нам кусочек?» Но летучие мыши ничего не знали: «Мы едим только комаров». Потом мышки увидели филина и спросили его: «Почему месяц такой маленький? Кто его ест? Дай и нам кусочек». Но филин ничего не знал. Тогда мышки спросили у орла, кто ест месяц и нельзя ли им кусочек. Орел ничего не ответил и улетел. Никто ничего не знал. Только коекто с зелеными глазами все знала, но она следила только за мышками и прыгнула на них. Это была кошка.

11. Once there was a child Who would like to be idle, But when came the time of meal He could not his lust conceal, Eating like a wolf a-wild, Though he's very mild; That extremely hungry child.

12. Мышонок Клаке жил хорошо. Он однажды повстречал своего друга. Это был мышонок Том. Они пошли играть в песок. А когда мама позвала их домой... Папа сказал: «Когда ты поешь, ты посмотришь мультфильм». А мультфильм был интересным - про Тома энд Джерри. Джерри всегда доставлял Тому неприятности, потому что он тоже хотел дать сдачи. А когда мультфильм закончился, они пошли есть, а потом пошли спать. Продолжение следует.
Более раннее введение второго языка в общение с ребенком (с первого месяца его жизни) помогает избежать слишком частого использования стратегии облегчения при встрече с трудными для произнесения словами на каждом из двух языков, а, следовательно, и более редкого смешения языков в его речи.

Ономатопичные названия часто помогают билингвальному ребенку четко ухватить основную идею высказывания и навсегда остаются в долгосрочной памяти.

Умение инициировать вопрос считается важным этапом в развитии языковой и коммуникативной компетенции ребенка, в совершенствовании его диалогического общения.

Рифма - вот главный инструмент к сердцу ребенка! Волк, голубка и дите становятся неким единым целым и вызывают улыбку, непременно развивая воображение.

Рассказ ребенка о нем самом в третьем лице может заметно повысить его внимательность к происходящим событиям, слышимой речи взрослых, реагировать на допущенные ошибки и за счет использования параллельных конструкций искоренить их. 


\begin{tabular}{|c|c|c|}
\hline 13. & $\begin{array}{l}\text { There lived in Cherepovets town A boy who liked } \\
\text { to climb up and down Avery thick and tremendous } \\
\text { pole; One day he climbed up so high That hit his } \\
\text { head on the sky And made in it a tremendous hole! }\end{array}$ & $\begin{array}{l}\text { Использование разнообразных синони- } \\
\text { мов, идиоматических и образных выра- } \\
\text { жений помогает развить не только } \\
\text { словарный состав, но и воображение и } \\
\text { языковую картину мира билигва. }\end{array}$ \\
\hline
\end{tabular}

В методике исправления ошибок нами выделены следующие приемы:

1) Объяснение грамматического явления или словоупотребления;

2) Исправления ошибки с просьбой повторить правильный вариант;

3) Просьба повторить сказанное, чтобы ребенок сам исправлял свои речевые ошибки;

4) Повторение того, что сказано ребенком, но без его ошибки и без привлечения внимания к ней;

5) Исправления должны быть понятны ребенку, нельзя требовать от него понимания, несоответствующих его возрастной группе.

6) Старайтесь подобрать шутливо-игровую форму исправления ошибки, чтобы дети взглянули на них с юмором.

7) Большего успеха добиваются те родители, которые в общении с ребенком ставят его в центр коммуникации, больше интересуются тем, о чем он говорит, чем тем, как он это говорит.

Взаимодействие языков наблюдается в речи билингва любого возраста, однако, интенсивнее всего проявляется в речевой деятельности ребенка, одновременно усваивающего два языка. Ошибки в речи детей-билингвов, одновременно усваивающих два языка, делятся на две категории: внутриязыковые, обусловленные их возрастными особенностями, и межъязыковые, обусловленные интерференцией. Билингвальный тип общения влияет и на реализацию интерференции, которая в одноязычных ситуациях может не наблюдаться или появляться редко. На этапах становления билингвальности количество ошибок в речи ребенка на одном языке может тоже стимулироваться активизацией другого языка, в котором действуют сходные правила. Возрастные ошибки детей в недоминантном языке могут быть как отклонением от нормы, так и отклонением от узуса (У́зус (лат. usus «применение, обычай, правило») - общепринятое носителями данного языка употребление языковых единиц, слов, устойчивых оборотов, форм, конструкций). Последние объясняются недостатком инпута, а при моноэтническом билингвизме - отклонениями от узуса и в самом инпуте, особенно если родитель, не являющийся носителем языка, на 
котором говорит с ребенком, усваивал его в условиях своего общества. Отклонения от узуса особенно заметны на фонетическом уровне, так как не отражают обычного для жителей определенной страны произношения. Когда усвоение нормы одного языка идет более быстрыми темпами, чем усвоение нормы второго языка, в речи ребенка начинает проявляться интерференция. Поэтому, чем дольше длится стадия сбалансированного общения с ребенком на двух языках, тем ближе ребенок к усвоению двух монолингвальных норм, a иногда и третьей - билингвальной нормы. В период становления моноэтнического билингвизма у детей интерференция наблюдается редко на фонетическом и грамматическом уровне, но факты ее проявления в дальнейшем учащаются, если она присутствует в речи в речи взрослых, от которых дети усваивают языки. Интерференция действует как наименее осознанная билингвами форма взаимодействия двух языков и активнее всего проявляется на этапе убывания билингвальности в тех аспектах недоминантного языка, в которых проявляются наиболее слабо усвоенные явления. Это объясняется возрастающей компетенцией в Я1 при ее убывании в Я2, в связи с чем влияние Я, усиливается. Даже на лексическом уровне, где при формировании билингвизма у маленьких детей интерференция практически отсутствует, она появляется все чаще при выборе лексикосемантических вариантов слова. Словообразовательная активность ребенкабилингва проявляется в ошибочных, ненормативных номинациях, которые часто связывают с действием лексико-семантической интерференции. В номинативной деятельности ребенка-билингва калькирование является одним из способов заполнения лексических лакун в любом из двух языков и основано на способности ребенка к спонтанному переводу и сопоставлению лексико-семантического содержания слов. Оно характерно для периода, следующего за дифференциацией языков. Более раннее введение второго языка в общение с ребенком (с первого месяца его жизни) помогает избежать слишком частого использования стратегии облегчения при встрече с трудными для произнесения словами на каждом из двух языков, a, следовательно, и более редкого смешения языков в его речи. Существует несколько причин интерференции в области грамматики при одновременном усвоении двух языков:

- объективные, прогнозируемые явления, т.е. выявляемые на основании контрастивного анализа различия двух языковых систем;

- сходные явления в двух языках, стимулирующие применение стратегии облегчения, или оптимального выбора; 
- вторичная интерференция как результат усвоения ребенком интерференции из инпута. Некоторые проявления интерференции на самом деле являются возрастными ошибками, если такие же наблюдаются и у детеймонолингвов. Особенностью усвоения семантической стороны языков билингвальными детьми является то, что они подавляют стратегию взаимоисключения, которая наблюдается у одноязычных детей на пике их номинативной активности. Особенности использования этой стратегии отличаются на разных этапах становления билингвального лексикона. В начале периода номинативной активности билингвальный ребенок использует ее в виде стратегии облегчения, выбирая из двух языков артикуляторно более легкие слова. На следующем этапе стратегия взаимоисключения подавляется в одноязычной коммуникации, особенно активно - при общении на доминантном языке. В период детского эквилингвизма она полностью отсутствует.

Период номинативной активности у детей-билингвов характеризуется накоплением межъязыковых функциональных эквивалентов, которые дублируют наименования объектов и их свойств на двух языках. К двухлетнему возрасту интервал между наименованием одного и того же референта с помощью единиц двух языков все более сокращается, и номинативная деятельность детей начинает характеризоваться параллельным развитием, т.е. появление номинации на одном языке сразу же стимулирует ее введение на другом языке. Длительность периода параллельного развития двуязычной номинативной деятельности зависит от сбалансированности билингвизма.

Большая часть особенностей произношения детей-билингвов сходна с особенностями произношения их одноязычных сверстников и, в особенности, если речь идет о доминантном языке. Усвоение произношения звуков на более позднем этапе может быть обусловлено его билингвизмом. При формировании билингвизма большинство субституций звуков двуязычных детей соответствуют субституциям звуков одноязычных детей. Многие билингвы, как и одноязычные дети, предпочитают не использовать в речи трудные для произношения звуки и заменяют их звуками более легкими в артикуляции. Данная тактика прослеживается как в русском, так и в английском языке.

Исследование билингвизма имеет более чем столетнюю историю и также включает в себя вопросы взаимосвязи языка и мышления, взаимодействия языка и сообщества, языка и личности. Традиционно принято выделять 
начальный, классический и современный этапы изучения проблемы двуязычия.

Процесс формирования детского моноэтнического билингвизма комплексное явление, поэтому были разработаны различные подходы и принципы для его упрощения и систематизации. Так, базовыми принципами являются: персональный, предметно-тематический, локальный, принцип стороннего слушателя, темпоральный и смешанный.

В зависимости от разных критериев выделяют младенческий, детский, взрослый, моноэтнический, биэтнический, продуктивный, непродуктивный, рецептивный билингвизм.

На современном этапе развития науки о билингвизме проявились не изученные области детского двуязычия, такие как поведение двуязычных детей в межкультурной коммуникации, многоаспектное изучение переключения кодов, особенности усвоения языков в гендерном аспекте и специфика формирования билингвизма близнецов. Так, например, одним из самых остро обсуждаемых вопросов на сегодняшний день является тезис о билингвальности как языковой норме.

В качестве возможной рекомендации можем посоветовать родителям билингвального ребенка на корню пресекать всяческое коверкание слов и править, пока не ощущается эффекта приниженности ребенка фактом допущенной ошибки; обращать особое внимание на содержательную сторону текстового окружения ребенка в любом языковом пространстве. Формирование ценностных и валеологических ориентиров важно не только в каждом конкретном языковом сообществе, но и в глобально-мировом масштабе тоже; дополнительно проговаривать семантико-экспрессивную наполненность каждого слова и словосочетания в каждом из воспринимаемых иностранных языков.

В заключении хотелось бы порекомендовать, непременно, как можно больше включать в совместную с ребенком деятельность прочтение и прослушивание фольклорных произведений с многочисленными суффиксально-префиксальными особенностями, чтобы этот потенциал стал базой для дальнейшего речевого и культурного развития ребенка.

\section{Список литературы}

1. Вайнрайх У. Языковые контакты: Состояние и проблемы исследования /пер. с англ. - Киев, 1979. - 261 с.

2. Гвоздев А.Н. Вопросы изучения детской речи. - СПб, 2007. -472 с. 
3. Коровушкин В.П., Чиршева Г.Н. Взаимодействие английского и русского языков в речи ребенка-билингва в возрасте от года до двух лет: (Из опыта семейного обучения) \ Проблемы раннего обучения ИЯ. - Череповец, 1992. - C. 19-21.

4. Леонтьев А.А. Основы психолингвистики, -М.: Смысл, 1997. - 287 с.

5. Леонтьев А.А. Национально-культурная специфика речевого поведения - М.: Наука, 1977. - 152 с.

6. World Health Organization Рекомендации BO3 https://www.who.int/

7. Плунгян В.А. Почему языки такие разные. Популярная лингвистика. М.: Русистика, 2018. - 272 с.

8. Leopold W.F. A child's learning of two languages II Second Language acquisition: A Book of Readings \Ed. E.M. Hatch. - Rowley, Mass., 1978. - P.23-32

9. Saunders G. Bilingual children: From birth to teens. - Clevedon, 1988. -274 p.

(C) Т.Н. Савчук, О.Г Ивкина, Е.Г Буденная, В.А. Афанасьева, 2020 